\title{
Clinical Significance of Viral Genome Persistence in the Myocardium of Patients with Dilated Cardiomyopathy
}

\author{
Ewa Nowalany-Kozielska ${ }^{a}$ Monika Kozieła Dorota Domal-Kwiatkowskac \\ Celina Wojciechowska ${ }^{a}$ Wojciech Jacheća Damian Kawecki ${ }^{a}$ \\ Andrzej Tomasik ${ }^{a} \quad$ Brygida Przywara-Chowaniec ${ }^{a} \quad$ Ludmiła Węglarz $^{c}$ \\ Edyta Reichman-Warmusz ${ }^{b}$ Romuald Wojnicz ${ }^{a, b}$
}

Departments of a Cardiology and ${ }^{\mathrm{b} H i s t o l o g y, ~ S c h o o l ~ o f ~ M e d i c i n e ~ w i t h ~ t h e ~ D i v i s i o n ~ o f ~ D e n t i s t r y, ~ M e d i c a l ~ U n i v e r s i t y ~}$ of Silesia, Zabrze, and 'Department of Biochemistry, School of Pharmacy and the Division of Laboratory Medicine, Medical University of Silesia in Katowice, Sosnowiec, Poland

\section{Key Words}

Dilated cardiomyopathy $\cdot$ Heart failure $\cdot$ Endomyocardial biopsy · Viral genome

\footnotetext{
Abstract

Background: The impact of myocardial viral persistence on the clinical outcome of patients with dilated cardiomyopathy (DCM) is still open to question. Methods: Fifty-two patients with DCM were enrolled and followed for a median of 3.8 years with respect to death or heart transplantation. Studied patients were clinically stable for at least 6 months before hospitalization. They underwent coronary angiography and endomyocardial biopsy. Specimens were examined by histo- and immunohistochemistry, and the viral genomes of parvovirus B19, cytomegalovirus (CMV), Coxsackie B virus (CVB), and hepatitis $B$ and $C$ viruses were studied by real-time polymerase chain reaction. Results: Forty-two out of 52 patients were available for clinical follow-up. The viral genome was detected in the myocardium of 32 out of 42 patients.
}

Among the viruses studied, CMV and CVB were the most frequently found. Nine out of 42 patients achieved the predefined study end point. No statistically significant correlation was found between the presence of a persistent viral genome and study end point. No statistically significant relationship between viral genomes studied and immunohistology results was detected. Conclusions: High prevalence of a viral genome in the myocardium of patients with DCM did not have an influence on their long-term clinical outcome.

(c) 2016 S. Karger AG, Basel

\section{Introduction}

Dilated cardiomyopathy (DCM) has been defined as a heart muscle disease of unknown origin with dilation of the ventricles [1]. Although DCM consists of a heterogeneous group of diseases, it is generally accepted that viral myocarditis (MCI) may underlie the disease [2]. In fact,

\section{KARGER 125}

(c) 2016 S. Karger AG, Base

$0300-5526 / 16 / 0586-0350 \$ 39.50 / 0$

E-Mail karger@karger.com

www.karger.com/int
Monika Kozieł

Department of Cardiology, School of Medicine with the

Division of Dentistry, Medical University of Silesia

Skłodowskiej-Curie 9, PL-41-800 Zabrze (Poland)

E-Mail kozielmonika@ poczta.fm 
clinical data and molecular techniques have confirmed that up to $50 \%$ of DCM cases appear to be caused by MCI [2-4].

In Europe, the most common causes of viral myocarditis are related to the hepatitis $\mathrm{C}$ virus (HCV), Coxsackie virus B (CVB), adenoviruses, parvovirus B19 (PVB19), and cytomegalovirus (CMV) [5]. In addition, recent data suggest that the type of virus may also play a significant role in the clinical outcome in MCI/DCM patients [6]. However, there is still uncertainty about the viral persistence in the myocardium [7-10].

Because available data concerning the impact of myocardial viral persistence on clinical outcome are still scarce and contradictory, we investigated whether the virus genome influenced long-term clinical outcome of patients with DCM.

\section{Methods}

\section{Study Group}

Between 2004 and 2007, we screened 196 patients with chronic heart failure (HF). Based on the inclusion and exclusion criteria as presented below, 52 patients with confirmed DCM etiology (34 males, 18 females; mean age $\pm \mathrm{SD}=44.9 \pm 10.7$ years) were ultimately enrolled. All of them were in the New York Heart Association (NYHA) functional classes II and III, and had a left ventricu$\operatorname{lar}(\mathrm{LV})$ ejection fraction smaller than $40 \%$. The mean duration of symptoms was 26.3 months. All patients had coronary angiography and right ventricle endomyocardial biopsy. Moreover, all of them were treated with angiotensin convertase inhibitors or angiotensin receptor blockers, $\beta$-blockers, spironolactone, and diuretics at the maximal tolerated doses according to guidelines. No other therapies were allowed during the follow-up observations. The inclusion criteria were as follows: clinically confirmed DCM and completed endomyocardial biopsy. Patients were excluded if any of the following were present: other than DCM HF clinical presentation, unstable HF within the previous 3 months, nonpharmacological HF therapy at baseline, any changes in coronary arteries, valvular disease (except relative mitral and/or tricuspid regurgitation), clinically significant hepatic or renal disease, endocrine disease (except impaired glucose tolerance), drug or alcohol abuse, less than 18 years of age, and lack of informed consent from the patient.

The study was approved by the ethics committee of the Medical University of Silesia (NN-6501-7/I/07).

\section{Noninvasive Assessment}

Complete M-mode, 2-dimensional, and Doppler echocardiography examinations were performed with a $2.5-\mathrm{MHz}$ transducer using a Hewlett-Packard SONOS 5500, Vivid 4, or Vivid 7 focused on the LV ejection fraction, LV systolic and LV diastolic volumes, LV diastolic diameter, and mitral regurgitation severity. Routine electrocardiography and 24-hour ECG monitored ventricular premature beats. The NYHA class was used to assess functional capacity.

Clinical Significance of Viral Genome

Persistence

\section{Endomyocardial Biopsy}

Endomyocardial biopsy was performed using the Cordis Bioptome. A minimum of 5 specimens were obtained from the right side of the ventricular septum, which were promptly immersed in sterile saline and transported on ice to the laboratory. Specimens were routinely distributed as follows: 4 for histology and 1 for polymerase chain reaction (PCR) study. Biopsy specimens for the histological examination were fixed in $3 \%$ glutaraldehyde with $0.1 \mathrm{M}$ cacodylic buffer at pH 7.4 and were paraffin-embedded. For immunohistochemistry, specimens were fixed for $20 \mathrm{~min}$ in acetone at room temperature, immersed in embedding medium (OCT Compound, Miles Inc.), and stored in liquid nitrogen until tested. Specimens were cut into $5-\mu \mathrm{m}$-thick slices on a Cryotome $\mathrm{FSE}^{\circledR}$ Thermo Scientific Shandon Microtome, air-dried at room temperature, and assayed.

\section{Histochemistry Study}

For histological examination, sections were routinely stained with hematoxylin and eosin and Masson trichrome stains. Histopathological examination was performed independently by two investigators according to the Dallas classification [11]. The diagnosis of myocarditis was made by consensus.

\section{Immunohistochemistry Study}

For immunohistochemistry, frozen sections (5 $\mu \mathrm{m}$ thick) were incubated with murine monoclonal antihuman antibodies: anti-HLA-class II (DR antigens), $\alpha$-chain (clone TAL.1B5), anti-HLA-class I (ABC antigens; clone W6/32), anti-CD3 for T lymphocytes (clone T3-4B5), and antimacrophages (clone EBM11). All antibodies were from DAKO A/S (Glostrup, Denmark). The dilution of the primary antibody was verified in our laboratory in a series of pilot experiments. Antibodies were diluted in Tris-buffered saline, $\mathrm{pH} 7.6$, and samples were incubated for $60 \mathrm{~min}$ at room temperature in a humidified chamber. The En-Vision method (DAKO En-Vision Kit/Alkaline Phosphatase Detection System) was used according to the manufacturer's instructions. The bound primary antibody was detected using the New Fuchsin Substrate System (DAKO A/S). The immunohistological examination of biopsy specimens was made by two investigators independently, blinded to clinical features and histopathological diagnosis. Specimens with upregulation of HLA-DR and HLA-ABC together with the detection of more than $14 \mathrm{CD} 3+$ infiltrating lymphocytes and/or CD68+ macrophages were considered positive for myocarditis. All immunohistological results were obtained with the use of the NIKON Eclipse $80 i$ microscope with DS-Fil digital camera and NIS Elements software from NIKON.

\section{Molecular Detection of Viral Genomes}

Genomic/viral DNA was isolated from biopsy specimens using a salting-out extraction method. Total RNA was extracted from tissues using a Trizol ${ }^{\circledR}$ reagent (Invitrogen). In order to exclude possible RNA contamination, DNA extracts were treated with RNase A (MBI Fermentas). RNA extracts were treated with DNase I (RNeasy Mini Kit, Qiagen), according to the manufacturer's instructions. The quality of extracts was checked electrophoretically using $0.8 \%$ agarose gel stained with ethidium bromide (Sigma-Aldrich). The results were analyzed and recorded using the 1D Bas-Sys Gel Documentation System (Biotech-Fisher). Nucleic acid concentration was determined using a Gene- 
Table 1. Baseline characteristics of the enrolled patients $(n=52)$

\begin{tabular}{lc}
\hline Age, years & $44.9 \pm 10.7$ \\
Sex, M/F & $34 / 18$ \\
HF duration, months & $19.2 \pm 6.4$ \\
Atrial fibrillation & $5(11.9)$ \\
Left bundle branch block & $4(9.5)$ \\
LV ejection fraction, \% (N: $\geq 55)$ & $36.5 \pm 13.9$ \\
LV diastolic dimension, mm (N: M: 42-59, F: 39-53) & $59.2 \pm 12.4$ \\
LV systolic dimension, mm (N: 26-34) [23] & $45.7 \pm 15.8$ \\
NYHA (I-IV) & $1.9 \pm 0.8$ \\
NTproBNP, pg/ml (N: <100) & $612(373.2-1,919.5)$ \\
CRP, mg/l (N: <5) & $2.2(1.1-4.9)$ \\
Dallas criteria of myocarditis & \\
$\quad$ Active & $2(3.8)$ \\
$\quad$ Borderline & $9(17.3)$ \\
No & $41(78.8)$ \\
Immunohistochemistry-positive myocarditis & $19(36.5)$ \\
\hline
\end{tabular}

Values are expressed as means $\pm \mathrm{SD}, \mathrm{n}(\%)$, or medians (1st-3rd quartile). $\mathrm{N}=$ Norm.
Quant $^{\mathrm{TM}}$ pro RNA/DNA Calculator (Amersham Biosciences). For detection of viral genomes, real-time PCR was performed with deep-frozen and/or RNAlater-fixed biopsy specimens. The quantitative analysis was carried out with the use of an ABI PRISM 7000 Sequence Detection System (Applied Biosystems). Detection of the copy number of analyzed viruses was performed as described previously [12-14]. The copy numbers of HBV, CMV, PVB19, HCV, and CVB3 were evaluated using qPCR and SYBR Green I chemistry (SYBR Green QuantiTect PCR Kit, Qiagen) and RT-qPCR and SYBR Green I chemistry (SYBR Green Quanti-Tect RT-PCR Kit, Qiagen), respectively. The GAPDH gene (glyceraldehyde-3-phosphate dehydrogenase) was included as an endogenous positive control of the amplification and integrity of extracts. The samples with known copy numbers of analyzed viruses detected by ELISA were used as a positive control. All samples were tested in triplicate. Specificity of the PCR reaction was also confirmed by determining the characteristic melting temperature of each amplimer, and the PCR products were separated on $6 \%$ polyacrylamide gels and visualized with silver salts. The DNA and mRNA copy numbers of examined viruses were determined on the basis of the commercially available standard of $\beta$-actin (TaqMan ${ }^{\circledR}$ DNA Template Reagents Kit; PE Applied Biosystems). Oligonucleotide primers specific to analyzed viruses were designed and/or characterized using Primer Express 2.0 software (PE Applied Biosystems). The following oligonucleotide $5^{\prime}$ and $3^{\prime}$ primer sequences were used: CMV (sense: 5'-TTTTTAGCACGGGCCTTAGC-3'; antisense: 5' -AAGGAGCTGCATGATGTGAGC-3'), CVB3 (sense: $5^{\prime}$-CGGTACCTTTGTGCGCCTGT-3'; antisense: $5^{\prime}$-CAGGCCGCCAACGCAGCC- $3^{\prime}$ ), HCV (sense: $5^{\prime}$-CCCTGTGAGGAACTACTGTCTTCAC-3' ; antisense: $5^{\prime}$-TGCACGGGTCTACGAGACCTCCCG-3'), HBV (sense: $5^{\prime}$-TGCAGTATGGTGAGGTGAGCAATGC-3'; antisense: $5^{\prime}$-CCATGCAACTTTTTCACCTCTGCCT-3'), and PVB19 (sense: 5' -ATAAATCCATATACTCATT-3'; antisense: 5'-CTAAAGTATCCTGACCTTG-3').
Follow-Up and Clinical Outcomes

Patients were followed up in the routine outpatient clinics over a period of 5 years at 6 and 12 months, and then 1 visit per year up to the 5 th year. Subjects who did not complete 5 years of follow-up were recorded by mailed or telephone questionnaire. The study end points were as follows: death with all cases and heart transplantation or other surgical therapy for HF progression.

\section{Statistical Methods}

Normally distributed data are expressed as means \pm SD, but not-normally distributed data are presented as medians with interquartile range (25th and 75th percentiles). Student's t test was used to compare continuous data with normal distribution. Not-normally distributed data were compared using the Kruskal-Wallis $\mathrm{H}$ test. In addition, a $\chi^{2}$ test was used for nominal data. The analysis of the study end points was performed on an intention-to-treat basis with a two-tailed Fisher's exact test including all enrolled patients (except patients who withdrew). Death and surgical therapy were analyzed by a log-rank test for event-free survival analysis. All-cause mortality was summarized by construction of KaplanMeier curves for each group. Differences were considered statistically significant when $\mathrm{p}<0.05$. Statistical analysis was made with the SPSS version 16.0 software package (SPSS Inc.).

\section{Results}

Baseline characteristics of all patients with clinical follow-up are presented in table 1. Eight out of 52 patients (15.4\%) were excluded from the study because of resynchronization therapy in 5 patients and cardioverter-defibrillator implantation in 3 cases. Two out of 52 patients (3.8\%) withdrew from the study because they changed their place of residence. All enrolled patients were fol- 


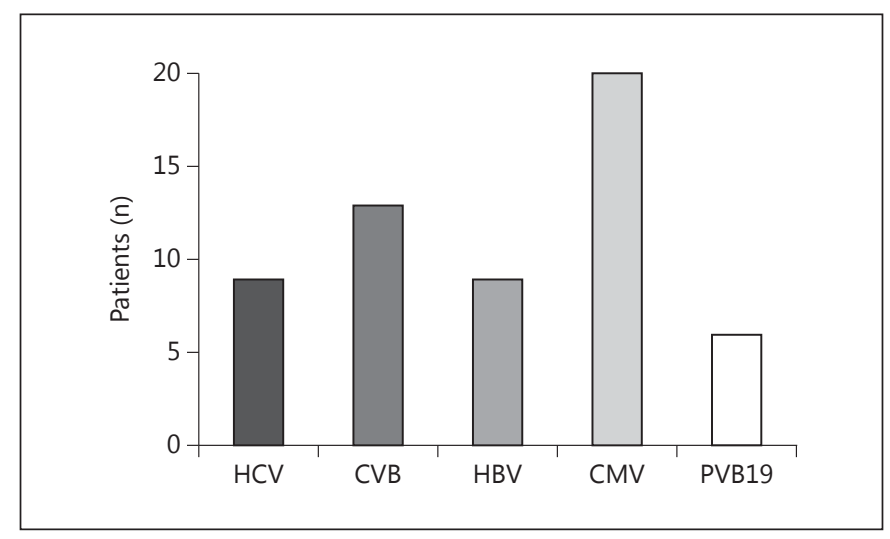

Table 2. The copy number of viruses studied by qPCR and RT-qPCR

\begin{tabular}{|c|c|c|c|c|}
\hline \multirow[t]{3}{*}{ Viruses studied } & \multicolumn{4}{|c|}{ Copy number of viral genome } \\
\hline & \multirow[t]{2}{*}{ range } & \multirow[t]{2}{*}{ median } & \multicolumn{2}{|c|}{ percentile } \\
\hline & & & 25 th & 75th \\
\hline 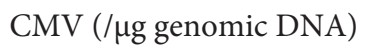 & $20-224$ & 74 & 37 & 113 \\
\hline CVB3 (/ $\mu \mathrm{g}$ total RNA) & $14-254$ & 44 & 40 & 141 \\
\hline $\mathrm{HCV}(/ \mu \mathrm{g}$ total RNA) & $28-179$ & 122 & 40 & 140 \\
\hline $\mathrm{HBV}(/ \mu \mathrm{g}$ genomic DNA) & $25-153$ & 55 & 40 & 85 \\
\hline PVB19 (/ $\mu$ g genomic DNA) & $12-34$ & 23 & 19 & 29 \\
\hline
\end{tabular}

Fig. 1. Number of DCM patients positive for viruses by PCR. As shown, CVB and CMV genomes in the biopsy specimens predominated.

Table 3. Characteristics of followed-up patients with and without virus genome in biopsy specimens

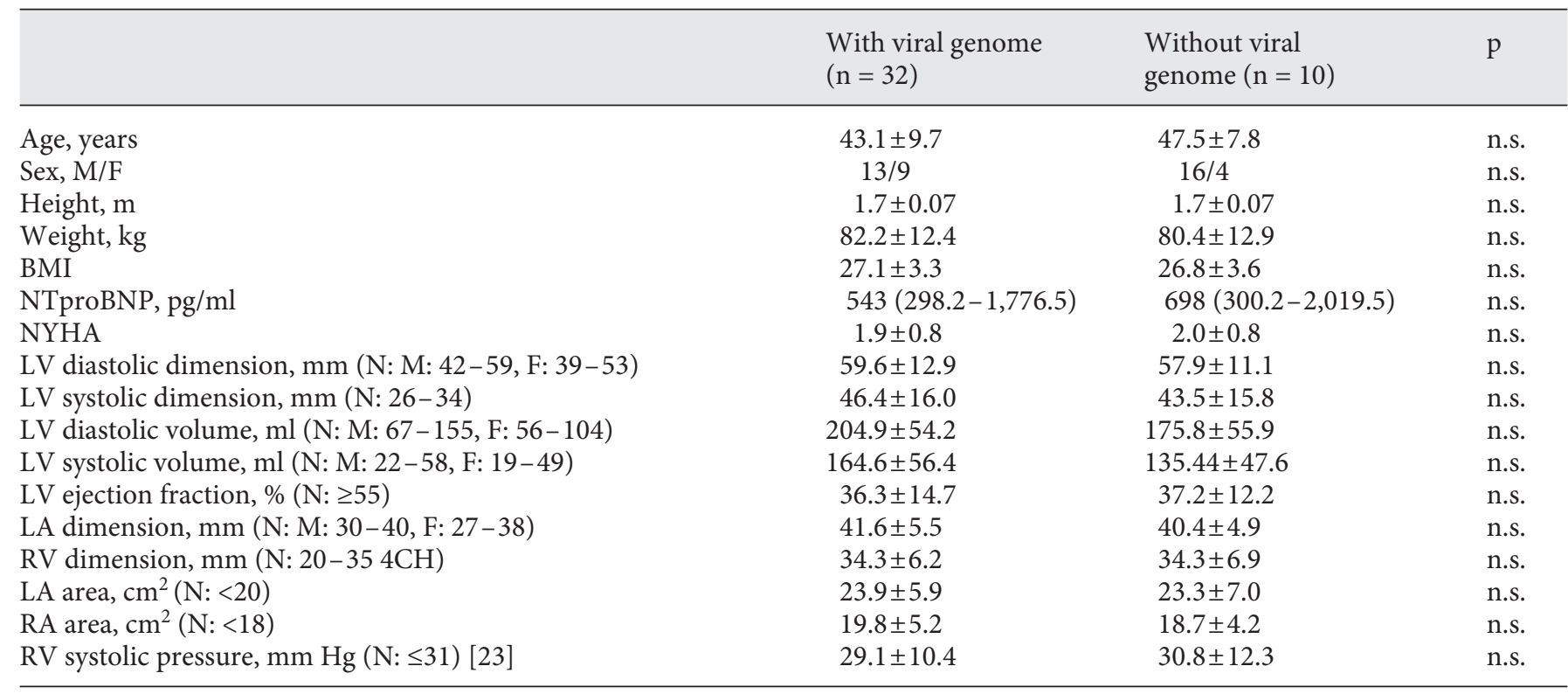

Values are expressed as means (SD), n, or medians (1st-3rd quartile). n.s. = Nonsignificant; $4 \mathrm{CH}=$ four-chamber view; $\mathrm{N}=$ norm.

lowed for a median of 3.8 years (range: $0.9-5.1$ ) with respect to death or heart transplantation. Finally, 42 out of 52 patients were available for clinical follow-up, yielding a follow-up rate of $80.8 \%$.

The real-time PCR results demonstrated that 32 out of 42 patients with DCM $(76.2 \%)$ had a viral genome for at least one type of virus studied. Accordingly, of the viral-positive subjects, 13 of them $(40.6 \%)$ were positive for one type of viral genome and 8 of them (25\%) were positive for two types of viral genomes. The remaining 11 cases $(34.4 \%)$ presented 3 or more types of viruses in the myocardium. Among the viral genomes studied, genetic material from CMV $(\mathrm{n}=20)$ and CVB $(\mathrm{n}=13)$ predominated (fig. 1). The copy numbers of studied viruses are presented in table 2 . After the PCR results, all patients were subdivided into two groups: those with 
persistence of at least one virus in the myocardium, and those without virus in the myocardium. There were no statistically significant differences between these two groups in their relation to the clinical parameters found (table 3).

Histopathological examination of endomyocardial biopsy samples according to the Dallas criteria were positive in 8 out of 42 patients (19\%), demonstrating active myocarditis in 1 case $(2.4 \%)$ and borderline myocarditis in 7 cases $(16.7 \%)$. In the remaining 34 cases, no myocarditis was found. On the contrary, inflammatory infiltrates by immunohistochemistry were detected in the biopsy specimens of 15 out of 42 subjects ( $35.7 \%$; table 1 ). Of the patients with positive immunohistology, 9 of the 15 cases $(60 \%)$ were positive for at least one type of viral genome detected by real-time PCR. However, in the current study there was no statistically significant relationship between the viral genome studied and immunohistology results.

During an average follow-up of 58.9 months, 9 out of 42 patients $(21.4 \%)$ achieved the predefined study end point of death ( 7 cases) and heart transplantation ( 2 cases). No relationship was found between the presence of persistent viral genome and study end point (fig. 2).

\section{Discussion}

The main finding of this study was that virus persistence did not influence long-term clinical outcome manifested here by death or heart transplantation in patients with DCM. In addition, we demonstrated that virus persistence was detected in the majority of patients with the disease irrespective of the histological features of myocarditis found. Among the viruses studied, the CMV and CVB genomes predominated.

As of yet, there is still no consensus concerning the prognostic significance of virus persistence in the myocardium of patients with DCM. The majority of previously published studies have suggested a significant impact of virus persistence on the clinical outcome $[15,16]$. However, the current results and previously published ones by Kindermann et al. [17] indicate that viral genome detection is not related to clinical outcome. This apparent disparity among the studies might be explained by a number of reasons. Firstly, different studied groups of patients were reported. Accordingly, patients with viral genomes and high incidence of active myocarditis or immunohistology-proven inflammatory response were predisposed to poor prognosis $[17,18]$. Conversely, a lack of concom-

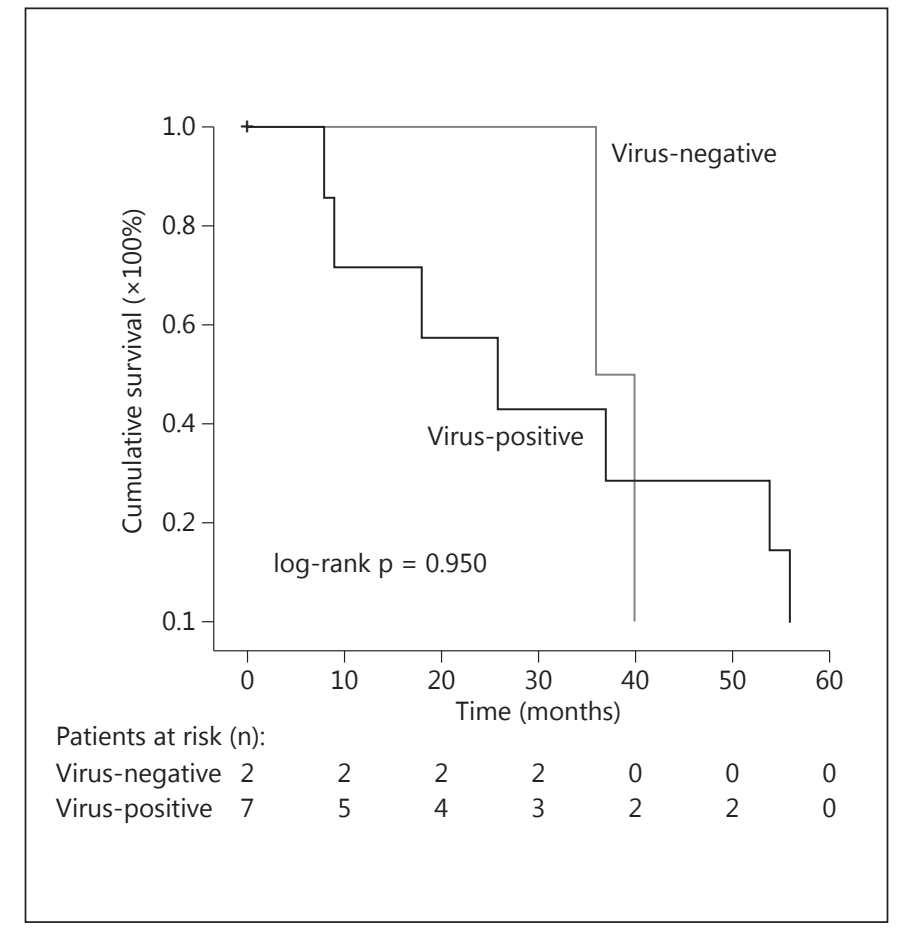

Fig. 2. Kaplan-Meier survival curves with regard to mortality and heart transplantation in virus-positive and virus-negative patients. There was no statistical difference in cumulative survival between the virus-positive and virus-negative patients.

itant inflammatory response in the myocardium with a viral presence was not related to poor outcome $[5,19]$. Secondly, not the virus presence per se but the phase of such presence (replication and lysogenic) in the myocardium seems to be a main predictor of poorer clinical outcomes. As reported, only the replication phase of the virus genome was associated with poor outcome $[17,18]$. On the contrary, the lysogenic stage of the viral persistence together with a lack of positive immunohistology for myocarditis was not related to long-term clinical outcome $[5,19]$.

In the current study we revealed the predominance of CMV and Coxsackie type B genomes in the biopsy specimens. This no doubt takes into consideration that CMV and enteroviruses are widely spread in humans but Coxsackie viruses have a broad tissue tropism to myocardium. On the other hand, only cytolytic replication of both viruses causes direct tissue damage. In contrary to our study, Bock et al. [20] reported that the PVB19 genome predominated in the patients suffering from DCM and myocarditis compared to noninflamed control hearts. 
The authors suggested that viral loads of more than 500 genomes per $\mu \mathrm{g} /$ tissue are a clinically relevant threshold for the maintenance of myocardium inflammation. In our study we observed a low number of PVB19 genome copies detected in biopsy specimens. These contradictory data may suggest population-related characteristics of different virus genomes present.

In the current study we could not detect a relationship between viral genome persistence and both histologically and immunohistologically detected myocardial inflammation. Our results are consistent with a previous study by Martin et al. [21], who showed no direct correlation between positive histopathology and positive PCR analysis. However, in contrast to the above-mentioned studies, Bowles et al. [22] stated in their study that viruses were more frequently detected in DCM patients with inflammatory infiltrates compared to subjects without inflammation. The rationale is that the inflammatory process is focally located, giving a sampling error of the biopsy inflammatory infiltration, which may have a significant influence on the association analysis between PCR and biopsy results. Furthermore, the phase of viral persistence, e.g. lysogenic and lytic, may (or not) have an influence on the inflammatory response in the myocardium.

\section{Conclusions}

In conclusion, the current study confirmed previous reports which stated that the virus presence in the myocardium does not influence the long-term clinical outcome of patients with DCM. In addition, our study revealed that the most commonly detected types of virus were CMV and CVB. It is clearly indicated that virus infections are strongly related to the population studied.

\section{Study Limitations}

The major limitation of this study was the relatively small number of patients ultimately included and the number of patients who completed the follow-up period. Thus, the ability to demonstrate any changes in clinical outcome was limited. On the other hand, the studied population was very restrictively selected, providing a homogenous group of patients which were ultimately enrolled and followed. Another limitation of the current study was that real-time PCR did not allow discriminating between the lysogenic and replication phase of the virus persistence in the myocardium.

\section{Disclosure Statement}

The authors report no conflicts of interest.

\section{References}

1 Elliott P, Andersson B, Arbustini E, et al: Classification of the cardiomyopathies: a position statement from the European Society of Cardiology Working Group on Myocardial and Pericardial Diseases. Eur Heart J 2008;29: 270-276.

2 McMurray J, Adamopoulos S, Anker S, et al: The Task Force for the Diagnosis and Treatment of Acute and Chronic Heart Failure 2012 of the European Society of Cardiology. Developed in collaboration with the Heart Failure Association (HFA) of the ESC. ESC Guidelines for the diagnosis and treatment of acute and chronic heart failure 2012. Eur Heart J 2012;1093:1-61.

3 Dec GW Jr, Palacios IF, Fallon JT, et al: Active myocarditis in the spectrum of acute dilated cardiomyopathies - clinical features, histologic correlates, and clinical outcome. N Engl J Med 1985;312:885-890.

4 Jin O, Sole MJ, Butany JW, et al: Detection of enterovirus RNA in myocardial biopsies from patients with myocarditis and cardiomyopa- thy using gene amplification by polymerase chain reaction. Circulation 1990;82:8-16.

5 Caforio AL, Pankuweit S, Arbustini E, et al: Current state of knowledge on aetiology, diagnosis, management, and therapy of myocarditis: a position statement of the European Society of Cardiology Working Group on Myocardial and Pericardial Diseases. Eur Heart J 2013;34:2636-2648.

6 Marholdt H, Wagner A, Deluigi CC, et al: Presentation, patterns of myocardial damage, and clinical course of viral myocarditis. Circulation 2006;114:1581-1590.

7 Schulz JC, Hilliard A, Cooper L Jr, Rihal CS: Diagnosis and treatment of viral myocarditis. Mayo Clin Proc 2009;84:1001-1009.

8 Andréoletti L, Lévêque N, Boulagnon C, Brasselet C, Fornes P: Viral causes of human myocarditis. Arch Cardiovasc Dis 2009; 102:559568.

9 Schonian U, Crombach M, Maser S, Maisch B: Cytomegalovirus-associated heart muscle disease. Eur Heart J 1995;16:46-49.
10 Kindermann I, Barth C, Mahfoud F, et al: Update on myocarditis. J Am Coll Cardiol 2012; 59:779-792.

11 Aretz HT: Myocarditis: the Dallas criteria. Hum Pathol 1987;18:619-624.

12 Giacca M, Severini GM, Mestroni L, et al: Low frequency of detection by nested polymerase chain reaction of enterovirus ribonucleic acid in endomyocardial tissue of patients with idiopathic dilated cardiomyopathy. J Am Coll Cardiol 1994;24:1033-1040.

13 Pauschinger M, Bowles NE, Fuentes-Garcia FJ, et al: Detection of adenoviral genome in the myocardium of adult patients with idiopathic left ventricular dysfunction. Circulation 1999;99:1348-1354.

14 Archard LC, Khan MA, Soteriou BA, et al Characterization of Coxsackie $B$ virus RNA in myocardium from patients with dilated cardiomyopathy by nucleotide sequencing of reverse transcription-nested polymerase chain reaction products. Hum Pathol 1998;29:578584.
Clinical Significance of Viral Genome

Persistence
Intervirology 2015;58:350-356 DOI: $10.1159 / 000443375$ 
15 Pankuweit S, Ruppert V, Eckhardt H, Strache D, Maisch B: Pathophysiology and aetiological diagnosis of inflammatory myocardial diseases with a special focus on parvovirus B19. J Vet Med B Infect Dis Vet Public Health 2005;52:344-347.

16 Why HJ, Meany BT, Richardson PJ, et al: Clinical and prognostic significance of detection of enteroviral RNA in the myocardium of patients with myocarditis or dilated cardiomyopathy. Circulation 1994;89:2582-2589.

17 Kindermann I, Kindermann M, Kandolf R, et al: Predictors of outcome in patients with suspected myocarditis. Circulation 2008; 118: 639-648.
18 Caforio AL, Calabrese F, Angelini A, et al: A prospective study of biopsy-proven myocarditis: prognostic relevance of clinical and aethiopathogentic features at diagnosis. Eur Heart J 2007;28:1326-1333.

19 Bowles NE, Rose ML, Taylor P, et al: Endstage dilated cardiomyopathy. Persistence of enterovirus RNA in myocardium at cardiac transplantation and lack of immune response. Circulation 1989;80:1128-1136.
20 Bock CT, Klingel K, Kandolf R: Human parvovirus B19-associated myocarditis. $\mathrm{N}$ Engl J Med 2010;362:1248-1249.

21 Martin AB, Webber S, Fricker FJ, et al: Acute myocarditis: rapid diagnosis by PCR in children. Circulation 1994;90:330-339.

22 Bowles NE, Ni J, Kearney DL, et al: Detection of viruses in myocardial tissues by polymerase chain reaction: evidence of adenovirus as a common cause of myocarditis in children and adults. J Am Coll Cardiol 2003;42:466-472.

23 Lang RM, Bierig M, Devereux RB, et al: Recommendations for chamber quantification. Eur J Echocardiography 2006;7:79-108. 